\title{
Effect of the solvent type and polymerization conditions on the curing kinetics, thermal and viscoelastic performance of poly(amide-imide) resins
}

\author{
Z. Rasheva*, L. Sorochynska, S. Grishchuk, K. Friedrich \\ Institut für Verbundwerkstoffe GmbH (Institute for Composite Materials), Erwin-Schrödinger-Str. 58, 67663 \\ Kaiserslautern, Germany
}

Received 26 September 2014; accepted in revised form 23 November 2014

\begin{abstract}
Isothermal and non-isothermal curing kinetics of both N-methyl-2-pyrrolidone (NMP) and N-methylimidazole (MI) based poly(amide-imide) (PAI) resins were investigated by DSC analysis using tightly closed high-pressure crucibles. Several exothermal peaks on the non-isothermal DSC-traces were observed and attributed to the reactions of different functional groups of PAI-resin. Furthermore the final conversion (polymerization degree) of PAI was determined under isothermal conditions, simulating three programs with the post-curing temperatures set as 215,240 and $270^{\circ} \mathrm{C}$. For the MI-PAI based resin, the conversion values were found to be much higher compared to those for the NMP-PAI system. Compared to NMP-based PAI-resin, a shift of the main exothermal peaks to the lower temperatures was observed in the non-isothermal kinetic investigations when MI was used as a solvent. This was accompanied with a reduction of activation energy $\left(E_{\mathrm{a}}\right)$ values, as up to a factor of 3 determined by the Flynn-Wall-Ozawa approach for all the main formation reactions. It indicates a catalytic effect of MI on the PAI polymerization.

In addition, conversion values were determined according to the Di Benedetto equation for both systems cured using open molds in the oven. Regardless the different post-curing temperatures, the conversion values were similar for all the samples. Thermal and viscoelastic properties as well as crosslink density $\left(n_{\mathrm{c}}\right)$ were also investigated for these systems. It was found that the MI-based samples demonstrate lower $n_{\mathrm{c}}$ values compared to the NMP-based ones at an almost two times higher storage modulus $\left(E^{\prime}\right)$ at room temperature.
\end{abstract}

Keywords: thermosetting resins, curing kinetics, activation energy, crosslink density, storage modulus

\section{Introduction}

Poly(amide-imide) resins (PAI) are mostly aromatic polymers attractive for a variety of high-performance applications. They are characterized by high thermal stability combined with excellent mechanical properties and chemical resistance [1,2]. Due to their outstanding sliding and abrasion behaviors they are used as a main polymer in various tribological coatings for sliding machine elements [1].

There are two main industrially applied routes of PAI synthesis: the trimellitic acid chloride (TMAC) and the isocyanate routes [3, 4]. By TMAC tech- nique, PAI is obtained as a product of polycondensation reaction between an aromatic diamine and trimellitic acid chloride (TMAC). This reaction takes place in organic solvents such as N-methyl-2pyrrolidone (NMP), dimethylacetamide (DMAC), dimethylformamide (DMF), etc. [5] with release of condensation products (hydrogen chloride $(\mathrm{HCl})$ and water $\left.\left(\mathrm{H}_{2} \mathrm{O}\right)\right)$ [3]. Therefore, applicable PAI resins are usually oligomers with quite high conversion of reactive groups of initial monomers. Such pre-polymer route in combination with careful cure procedure guarantees obvious prevention of void

\footnotetext{
${ }^{*}$ Corresponding author, e-mail: zdravka.rasheva@gmail.com (C) BME-PT
} 
formation due to strong reduction of amount of condensation byproducts.

$\mathrm{N}$-methyl-2-pyrrolidone (NMP) has proven itself over the years as the most suitable solvent for PAIresins. However, after the implementation of the $31^{\text {st }}$ Directive of the Dangerous Substances Classification 67/548/EEC (EEC: European Economic Community) in 2010 , there is a reclassification of NMP in Europe from Xi (irritating) to T (toxic). This fact makes an industrial use of NMP-containing PAI-resins complicate and therefore has activated a research on suitable alternative nontoxic solvents for PAI-resins.

The high solvent amount in PAI resins (ca. 60$80 \mathrm{wt} \%$ ) brings difficulties for investigation of the curing kinetics of these resins by thermal analysis. Some authors report the determination of the curing kinetics of polyimides using FTIR or NMR analysis [6-9]. Detecting the increase of the imide bands intensity during the chemical reaction, the conversion can be determined with quite high accuracy. For this purpose, however, the proportion of starting monomers must be known, which often is not the case for industrially purchased resins.

Another technique widely used for investigation of curing kinetics is thermal analysis using DSC. Usually, for the convenient DSC-measurement, standard aluminium ( $\mathrm{Al}$ )-crucibles are used, where the sample is not hermetically closed within the pans. However, in case of PAI-resin, the presence of high amount of solvent makes conventional DSC analysis inapplicable, since the exothermal curing reactions are overlapped with endothermal effects of solvent evaporation. On the other hand, the solvent is a media in which the PAI reactions occur. The postcuring reaction is extremely important for the final structure formation and occurs at elevated temperatures, when the solvent is evaporated [7, 10].

In the present study, effect of both curing conditions and solvent type on the polymerization kinetics and final properties of PAI resins was investigated. Nmethyl-2-pyrrolidone (NMP) usually used in the standard commercial formulations was replaced with the N-methylimidazole (MI) used as less dangerous alternative solvent. The curing kinetics was investigated by DSC analysis using high-pressure crucibles (HPC). In this case solvent remains trapped in the reaction system and its amount remains constant during the experimental run. The reaction in HPC represents an 'ideal' case, since under real conditions the solvent evaporates mostly during the initial stage of the curing. Although the HPC-measurements represent the 'ideal' case, they give an important insight into the curing behavior of PAIresins. Based on these experiments some conclusions regarding the curing process in 'real' case could be drawn.

Further, a non-toxic PAI-resin formulation containing MI as an alternative solvent was developed. MI is a heterocyclic compound, which belongs to the group of the tertiary amines. It has an aromatic structure and is mainly used as a solvent in various chemical processes [11] or as a catalyst for the curing of epoxy resins and polyurethanes [12]. The PAI resins based on $\mathrm{N}$-methylimidazole are more environmentally friendly and are very promising for development of a new generation of PAI systems. Apart from the curing kinetics, a particular attention was paid to the chemical structure, thermal behavior and viscoelastic properties of the cured final materials and results were compared to the state-of-the-art NMPbased PAI-systems.

\section{Experimental}

\subsection{Chemicals used}

In the present study an industrially produced PAIresin based on NMP (Rhodefthal 200 ES, Huntsmann Advanced Materials, Switzerland) was compared with a PAI-resin prepared in laboratory, based on MI. Both systems are manufactured following the TMAC technique $[3,13,14]$.

To prepare the PAI resin in laboratory, PAI pre-polymer in powder form (Solvay Advanced Polymers, USA) was mixed with the solvent $\mathrm{N}$-methylimidazole (Sigma Aldrich Chemie GmbH, Germany) in proportion 21 to $79 \mathrm{wt} \%$. In the present work, a low viscosity version of PAI, referred to as "Torlon ${ }^{\circledR}$ 4000T-LV' was used. Diamine component of Torlon ${ }^{\circledR} 4000 \mathrm{~T}$ consists of $30 \% \mathrm{~m}$-Phenylenediamine (m-PDA) and of 70\% 4,4'-Oxydianiline (ODA) [3, 14].

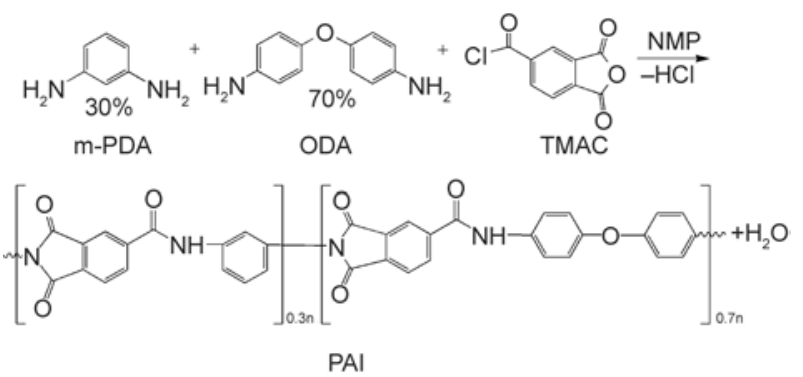

Figure 1. Synthesis of Torlon ${ }^{\circledR} 4000 \mathrm{~T}$ (TMAC route) $[14,13]$ 
The chemical reaction of the PAI-formation of Torlon ${ }^{\circledR} 4000 \mathrm{~T}$ is schematically presented in Figure 1. Polymerisation of the Rhodefthal 200 ES follows similar route, however an exact chemical content of the amine components is unknown. Both of the used PAI pre-polymers are partly pre-imidized [5].

\subsection{Samples preparation}

Investigation of the curing kinetics and the weight loss during chemical reaction was performed for the fresh prepared reactive mixtures of Torlon ${ }^{\circledR} 4000 \mathrm{~T}$ LV and Rhodefthal 200 ES further referred to as MI_TC(L) and NMP_TC(I), respectively. All further experiments (e.g. decomposition range, DMTA analysis viscoelastic properties and crosslink density) were performed using cured PAI-samples.

In order to study an effect of the post-curing conditions on the mechanical properties of PAI, several different curing programs were used for the manufacturing of the samples (Table 1). The list of the samples prepared is given in Table 2 where the postcuring temperature is mentioned in the sample name.

\subsection{Testing methods}

\subsubsection{Fourier transform infrared spectroscopy (FTIR) measurements}

FTIR measurements were performed on a Nicolet 510 spectrometer (Wisconsin, USA). Investigation of the PAI films was performed in ATR mode on $\mathrm{ZnSe}$ crystal in the transmission mode at $4 \mathrm{~cm}^{-1}$ spectral resolution in the wavelength range $4000-650 \mathrm{~cm}^{-1}$. Prior to the tests both PAI samples were vacuum dried at $50^{\circ} \mathrm{C}$ until constant weight.

\subsubsection{Thermogravimetric analysis (TGA)}

For the investigation of the PAI thermal stability a thermogravimetric analyzer DTG60 (Shimadzu, Japan) was used. For reactive systems, weight loss during the iso-thermal curing conditions was determined. These samples were tested at respective thermal curing programs (c.f. Table 1) in nitrogen atmosphere. Decomposition range of the final cured PAIsamples was determined in a temperature range from 25 to $600^{\circ} \mathrm{C}$ at a heating rate of $10^{\circ} \mathrm{C} / \mathrm{min}$ and a nitrogen flow of $30 \mathrm{~mL} / \mathrm{min}$. An initial samples weight was taken at about $10 \mathrm{mg}$.

\subsubsection{Differential scanning calorimetry (DSC)}

The investigations were carried out using DSC1 Mettler Toledo thermal analyzer (Giessen, Germany). Investigation of the curing kinetics of the reactive PAI mixtures by the conventional DSC method, when sample was placed in open Al-crucibles, is particularly difficult due to the high solvent content. In standard aluminum crucibles the reaction peak (exothermic) is overlapped by the peak of the solvent evaporation (endothermic). In order to avoid such effects, DSC measurements were carried out in $40 \mu \mathrm{L}$ gold-plated steel high-pressure crucibles (HPC) (called as 'ideal' case). The samples

Table 1. Applied curing programs

\begin{tabular}{|c|c|c|c|c|}
\hline Curing algorithm & Program 1 & Program 2 & Program 3 & Program 4 \\
\hline Start temperature & \multicolumn{4}{|c|}{$70^{\circ} \mathrm{C}$} \\
\hline First heating step & \multicolumn{4}{|c|}{$20 \mathrm{~min}$; from $70^{\circ} \mathrm{C}$ to $180^{\circ} \mathrm{C}$} \\
\hline First tempering step & \multicolumn{4}{|c|}{$20 \min$ at $180^{\circ} \mathrm{C}$} \\
\hline Second heating step & $\begin{array}{c}20 \mathrm{~min} ; \\
\text { from } 180^{\circ} \mathrm{C} \text { to } 215^{\circ} \mathrm{C}\end{array}$ & $\begin{array}{c}30 \mathrm{~min} ; \\
\text { from } 180^{\circ} \mathrm{C} \text { to } 240^{\circ} \mathrm{C}\end{array}$ & $\begin{array}{c}30 \mathrm{~min} \\
\text { from } 180^{\circ} \mathrm{C} \text { to } 270^{\circ} \mathrm{C}\end{array}$ & $\begin{array}{c}45 \mathrm{~min} ; \\
\text { from } 180^{\circ} \mathrm{C} \text { to } 290^{\circ} \mathrm{C}\end{array}$ \\
\hline Second tempering step & $1 \mathrm{~h}$ at $215^{\circ} \mathrm{C}$ & $1 \mathrm{~h}$ at $240^{\circ} \mathrm{C}$ & $1 \mathrm{~h}$ at $270^{\circ} \mathrm{C}$ & $20 \mathrm{~h}$ at $290^{\circ} \mathrm{C}$ \\
\hline
\end{tabular}

Table 2. An overview of the samples tested

\begin{tabular}{|c|c|c|c|}
\hline Sample name & Solvent used & $\begin{array}{c}\text { Resin origin } \\
\text { (industrial or laboratory prepared) }\end{array}$ & Curing program used \\
\hline NMP_TC(I)_215 & \multirow{4}{*}{ N-methyl-2-pyrrolidone (NMP) } & \multirow{4}{*}{ Industrial } & 1 \\
\hline NMP_TC(I)_240 & & & 2 \\
\hline NMP_TC(I)_270 & & & 3 \\
\hline NMP_TC(I)_290 & & & 4 \\
\hline MI_TC(L)_215 & \multirow{4}{*}{ N-methyl imidazole (MI) } & \multirow{4}{*}{ Laboratory } & 1 \\
\hline MI_TC(L)_240 & & & 2 \\
\hline MI_TC(L)_270 & & & 3 \\
\hline MI_TC(L)_290 & & & 4 \\
\hline
\end{tabular}


were tested at iso-thermal conditions using the temperature programs, given in Table 1.

For the determination of the activation energy reaction, non-isothermal DSC tests of uncured PAI samples were done in the temperature range of 70 $350^{\circ} \mathrm{C}$ at different heating rates $\left(3,5.5\right.$ and $\left.7{ }^{\circ} \mathrm{C} / \mathrm{min}\right)$. Determination of the glass transition temperature $\left(T_{\mathrm{g}}\right)$ of cured PAI-resins is not an easy task due to the post-curing reactions occurring at high temperatures with elimination of the reaction by-products. From that reason, the cured pure PAI samples were tested by DSC with stochastic temperature modulation $\left(\right.$ TOPEM $^{\circledR}$ ) allowing distinguishing between the total, reversible and non-reversible signals. The total heat flow signal is equivalent to the conventional DSC and is divided for reversible (relaxation related) and non-reversible (kinetics related) signals. For DSC, the measurement temperature range was from 0 to $300^{\circ} \mathrm{C}$ (or to $350^{\circ} \mathrm{C}$ in some cases), using a heating rate of $2 \mathrm{~K} / \mathrm{min}$ with a stochastic modulation of $0.5 \mathrm{~K} / \mathrm{s}$, in nitrogen atmosphere. The glass transition temperature $\left(T_{\mathrm{g}}\right)$ was determined as a heat capacity drop in the curves of the reversible signal.

\subsubsection{Dynamic mechanical thermal analysis} (DMTA)

The viscoelastic properties (storage modulus $E^{\prime}$ and the damping factor $\tan \delta$ ) of the cured PAI-samples were measured by mean of a dynamic mechanical thermal analyzer DMA Q800 TA Instruments (New Castle, USA). For these studies, samples of pure PAI-resins were prepared as thin films with dimensions of approx. $4 \mathrm{~mm} \times 12 \mathrm{~mm} \times 0.3 \mathrm{~mm}$ and tested in tension mode in the temperature range of 0 $375^{\circ} \mathrm{C}$, at a frequency of $10 \mathrm{~Hz}$, amplitude of $20 \mu \mathrm{m}$ and a heating rate of $3^{\circ} \mathrm{C} / \mathrm{min}$.

\section{Results and discussion}

The analysis of the FTIR spectra of both powdered Torlon 4000T-LV and dried Rhodefthal 200ES PAIoligomers showed that both of the studied PAIresins are quite identical by their chemical structure.

\subsection{Non-isothermal curing}

At a non-isothermal DSC analysis of PAI in standard aluminum crucibles the exothermic polymerization process is fully overlapped with several endothermic peaks, which correspond to the evaporation of the solvent $\left(202^{\circ} \mathrm{C}\right.$ for NMP and $198^{\circ} \mathrm{C}$ for MI pure solvents), absorbed and reaction by-products. In order to avoid an evaporation of the volatile components and to preserve the constant weight during the DSC measurements, the high pressure crucibles (HPC) were applied for the investigation of the PAI cure kinetics.

Prior to these measurements, the pure solvents (e.g. NMP and MI) used for both reactive PAI-mixtures were also investigated by DSC in HPC (Figure 2). It is worthy to note that in contrary to NMP (Figure 2a) a small exothermal peak was observed for the pure MI (Figure 2b). It indicates a chemical reaction, which occurs, most probably, due to the oxidation reaction of MI in the presence of oxygen and water, absorbed from air [15]. This reaction is observed at relatively high temperatures (above $200^{\circ} \mathrm{C}$, Figure $2 \mathrm{~b}$ ). However, at real curing conditions the solvent evaporates before these temperatures achieved suggesting negligible effect of the MI on the polymerization of the MI_TC(L) resin. Nevertheless, it can affect the chemical structure of the PAI in the initial stage of the polymerization process (as long as MI is still present in the reactive system).

The non-isothermal DSC traces of the PAI reaction in the presence of NMP and MI performed in HPC are shown in Figures 3a and 3b, respectively. In order to make a deeper analysis and to evaluate a contribution of the main reactions in the total polymerization process, the DSC curves were deconvoluted using a Gauss-function (dash lines in Figure 3).

After deconvolution, five main reaction peaks at $\sim 100,150,180,250$ and $300^{\circ} \mathrm{C}$ are evident for both

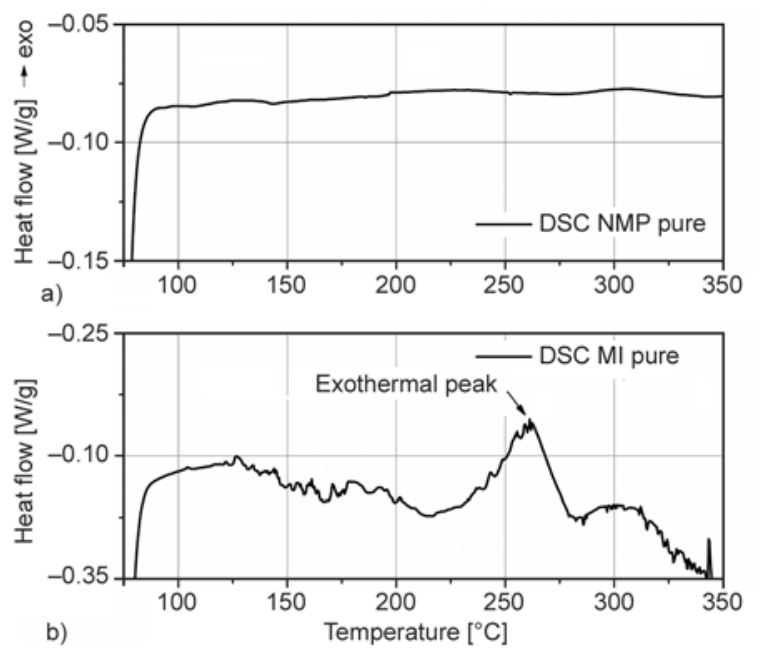

Figure 2. DSC (HPC) analysis of the pure solvents Nmethyl-2-pyrrolidon (a) and N-methyl imidazole (b) recorded at $10^{\circ} \mathrm{C} / \mathrm{min}$ heating rate 

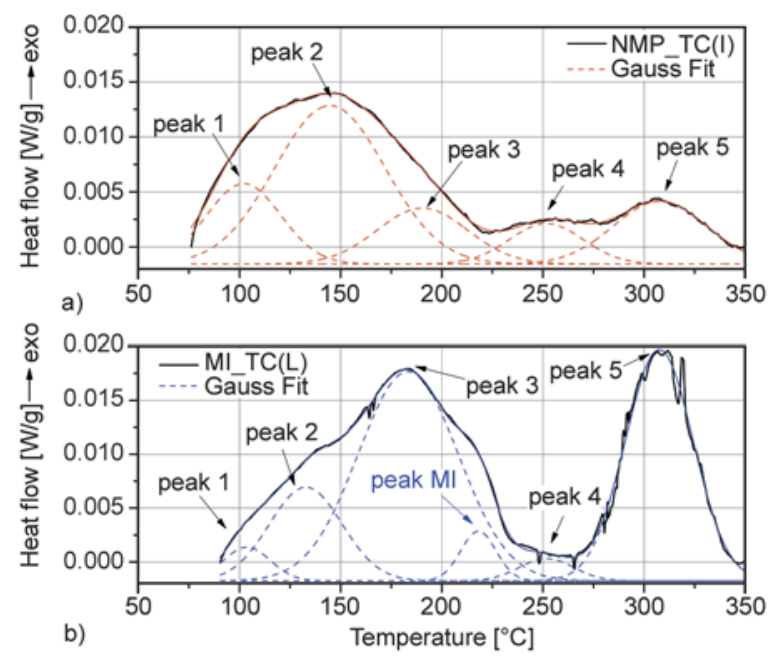

Figure 3. DSC traces of the NMP_TC(I) (a) and MI_TC(L) (b) PAI resins tested at $\overline{5} .5^{\circ} \mathrm{C} / \mathrm{min}$ heating rate in HPC and their Gauss deconvolutions. Note: All curves were normalized to the respective sample weight and shifted to the baseline for a better representation.

resins. They probably belong to the reactions of the different functional groups [16]. For the MI_TC(L) an additional reaction peak at $\sim 220^{\circ} \mathrm{C}$ observed in Figure $3 \mathrm{~b}$ can be very probably attriuted to the reaction peak of the pure solvent of Figure $2 b$. The shift of this peak to the lower temperature in comparison to the pure solvent can be due to the presence of PAI resin.

As it is known, the imidization reaction occurs in several stages [16]. Addition of the dianhydride to a diamine (aminoacylation) in a dipolar aprotic solvent such as MI and NMP leads to the formation of the intermediate poly(amic acids) (PAAc) due to the nucleophilic attack of the aminogroup on the carbonyl carbon of the anhydride. This reaction of an anhydride ring opening is influenced by the solvent used [17]. According to Kreuz et al. [16] and Lauver [18], the polyamic acid is formed in form of two con- formers with different steric structure, i.e. isophtalic (a) and terephtalic (b) shown in Figure 4. This reaction is fast and can occur even under relatively mild conditions. At the same time, the amidization reaction between amino groups of the $\mathrm{Cl}$-anhydride and the diamine occurs. Both of these reactions can be related to the peak 1 and 2 and schematically are presented in Figure 4 as reactions 1 and 2.

The next stage of the polyimidization is the cyclization of the PAAc (intermediate products (a) and (b) in Figure 4) via dehydration.

The high-temperature peaks on the DSC-traces at $\sim 180^{\circ} \mathrm{C}$ and $\sim 260^{\circ} \mathrm{C}$ were assigned to the imidization reactions of the different conformers of PAAc (reactions 3 and 4 in Figure 4) [19]. The last high temperature exothermal peak (peak 5 in Figure 3) was assigned to the post-curing reactions of sterically hindered reactive centers.

\subsection{Activation energy of polymerization}

The non-isothermal integral Flynn-Wall-Ozawa method was applied to estimate the activation energy $\left(E_{\mathrm{a}}\right)$ of the PAI curing reactions $[20,21]$ (Equation (1)):

$\ln \beta=\ln \frac{A E_{\mathrm{a}}}{g(\alpha) R}-5.333-1.052 \frac{E_{\mathrm{a}}}{R} \frac{1}{T}$

where $\beta$ is the heating rate $[\mathrm{K} / \mathrm{min}], E_{\mathrm{a}}$ is the temperature-dependent activation energy of the polymerization $[\mathrm{J} / \mathrm{mol}], R$ is the universal gas constant $R=8.314 \mathrm{~J} /(\mathrm{mol} \cdot \mathrm{K}), A$ is the pre-exponential factor $\left[\mathrm{s}^{-1}\right], g(\alpha)$ is the integration function of conversion, and $T$ is the peak temperature [K]. The temperatures of the individual peaks were taken from the Gauss deconvolution and the results are presented in Table 3.

As can be seen from the data, the activation energies of two first low temperature reactions, identified in

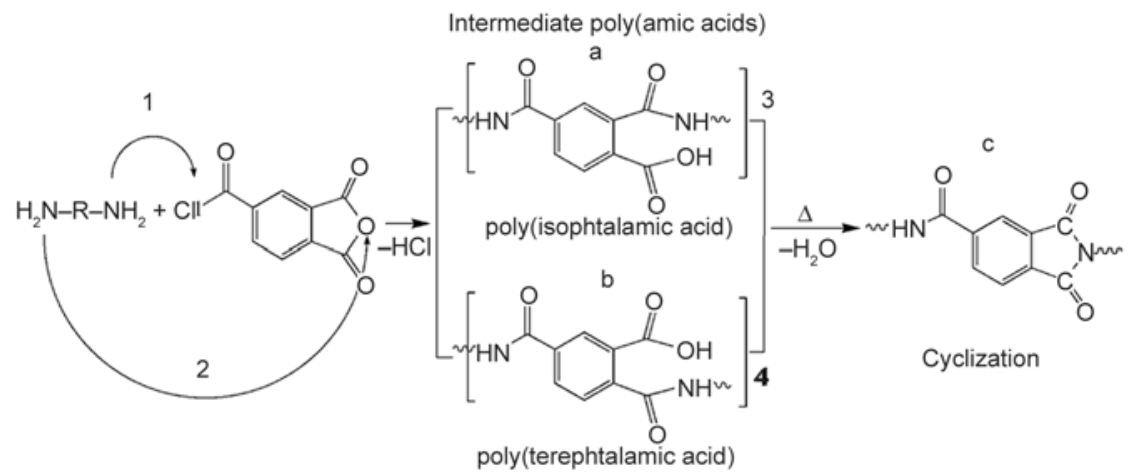

Figure 4. Scheme of the amidization (a, b) and imidization (e.g. cyclization of polyamic acid) reactions (c) 
Table 3. Reaction peak temperatures $\left(T_{\mathrm{p}}\right)$ at different heating rates and activation energy $\left(E_{\mathrm{a}}\right)$ results. The peaks are referred to the reactions proposed in Figure 4.

\begin{tabular}{|c|c|c|c|c|c|c|}
\hline \multicolumn{7}{|c|}{ NMP_TC(I) } \\
\hline Peak & 1 & 2 & 3 & MI-reaction & 4 & 5 \\
\hline Reaction & $\begin{array}{c}\text { Cl-anhydride }+ \\
\mathrm{NH}_{2}\end{array}$ & PAAc formation & $\begin{array}{l}\text { Cyclisation of } \\
\text { isophtalic } \\
\text { conformer }\end{array}$ & MI related & $\begin{array}{l}\text { Cyclisation of } \\
\text { terephtalic } \\
\text { conformer }\end{array}$ & $\begin{array}{c}\text { High } \\
\text { temperature } \\
\text { post-curing }\end{array}$ \\
\hline$T_{\mathrm{p}}$ at $3 \mathrm{C} / \mathrm{min}$ & 106 & 140 & 188 & - & 249 & 287 \\
\hline$T_{\mathrm{p}}$ at $5.5 \mathrm{C} / \mathrm{min}$ & 103 & 146 & 191 & - & 252 & 307 \\
\hline$T_{\mathrm{p}}$ at $7 \mathrm{C} / \mathrm{min}$ & 115 & 163 & 193 & - & 264 & 310 \\
\hline$E_{\mathrm{a}}[\mathrm{kJ} / \mathrm{mol}]$ & 42 & 46 & 292 & - & 102 & 89 \\
\hline \multicolumn{7}{|c|}{ MI_TC(L) } \\
\hline$T_{\mathrm{p}}$ at $3 \mathrm{C} / \mathrm{min}$ & 90 & 120 & 172 & 198 & 232 & 295 \\
\hline$T_{\mathrm{p}}$ at $5.5 \mathrm{C} / \mathrm{min}$ & 104 & 135 & 183 & 218 & 252 & 308 \\
\hline$T_{\mathrm{p}}$ at $7 \mathrm{C} / \mathrm{min}$ & 107 & 136 & 186 & 226 & 263 & 312 \\
\hline$E_{\mathrm{a}}[\mathrm{kJ} / \mathrm{mol}]$ & 52 & 60 & 93 & 56 & 59 & 128 \\
\hline
\end{tabular}

previous section as the amidization reaction of chloranhydride with diamine and formation of polyamic acid (1 and 2 in Figure 4), are slightly lower for the NMP-based resin than those for the MI-based one (42 and $46 \mathrm{~kJ} / \mathrm{mol}$ in contrast to 52 and $60 \mathrm{~kJ} / \mathrm{mol}$, respectively). Accordingly, their peak intensities are also higher (Figure 3). However, an onset of the polymerization reaction in the presence of MI takes place at lower temperatures indicating an activating effect of MI on the reaction onset.

For the peaks 3 and 4, assigned to the cyclization reaction of the different conformers of the polyamic acid, the $E_{\mathrm{a}}$ values determined for MI-based resin is much lower (93 and $59 \mathrm{~kJ} / \mathrm{mol}$ in contrast to 292 and $102 \mathrm{~kJ} / \mathrm{mol}$ for the NMP-based resin). The lower activation energy in this case can be explained by the catalytic effect of MI for the PAAc-cyclisation. At the same time, this solvent is known for its catalytic effect among other nucleophilic reactions in acidic conditions $[16,22,23]$. In addition, there is a direct correlation between the basicity and the nucleophilicity: increase of the basicity increases the nucleophilicity [24] and, accordingly, the reaction rate $[10,25]$. Taking into account the fact that MI has a higher $\mathrm{pH}$ value than $\mathrm{NMP}\left(\mathrm{pH}_{\mathrm{NMP}}=7.7-8 ; \mathrm{pH}_{\mathrm{MI}}=\right.$ 9.5-10.5) $[26,27]$ it can be supposed that MI could bring more benefits as media for the PAI reaction than NMP. The determined $E_{\mathrm{a}}$ value for the high-temperature reactions (peak 5 in Table 3 ) in MI-media is much higher than that for the NMP-based resin, however, both values are comparable with the data determined for the industrial resins being about $96 \mathrm{~kJ} / \mathrm{mol}$ [16].

It is noteworthy, that the peak intensity of the isophtalic conformer for MI_TC(L) sample (peak 3 in
Figure 3) is much higher compared to the reaction peak of terephtalic one (assigned as peak 4), whereas for the NMP-based PAI resin these peaks demonstrate similar intensity. Reaction of both the conformers is strongly dependent on the media and they are different by their thermodynamic stability reacting at the different speed and temperature. Thus, NingJo Chu etc. has found that terephtalic conformation is thermodynamically more stable than the isophtalic one due to the stronger ability to build the hydrogen bonds with NMP and, thereof, reacts at higher temperatures. Moreover, the ratio of tere- to isophtalic isomers in NMP solution is 3 to 1 found by NMR analysis whereas in dimethylacetamide (DMAc) this ratio was found to be lower (1 to 1) [28]. Since MI used as solvent in this work is hardly able to solvate PAAc through the hydrogen bonding, formation of the low-energy isophtalic-conformation is preferable and causes the lowering the reaction temperature and activation energy. Unfortunately, there is no literature known for authors studying the conformation of polyamic acid isomers in MI solvent. On the other hand, the NMP based PAI resin is commercial product, and its exact chemical structure is unknown and presence of some additives cannot be excluded.

The last high temperature reaction peak can be attributed to the post-curing (probably further imidization reactions). The activation energy of this chemical process is higher for the MI-PAI resin $(128 \mathrm{~kJ} / \mathrm{mol}$ compared to $89 \mathrm{~kJ} / \mathrm{mol}$ for the NMP-based resin). Taking into account obviously higher enthalpy and much stronger intensity of this exothermal peak for the MI-resin against NMP-based one, it can be concluded that there are more functional groups react- 
ing. However, the higher completeness of the previous reactions in presence of MI (discussed above) should cause stronger steric hindrances for the later stage of post-curing reactions. Therefore, different reaction types could probably take place during hightemperature post-curing of NMP and MI based PAIresins. This is also partially confirmed by difference in the respective $E_{\mathrm{a}}$ values for both resins. It could be possible that reaction products of MI in the structure of PAI-network are responsible for this. However, it was not a topic of this work and should be investigated in depth in the future. Nevertheless, it is worthy to note that the reaction peak of low intensity observed at $200-250^{\circ} \mathrm{C}$ for the MI-based resin has no correspondent peak for NMP-based PAI. The estimated $E_{\mathrm{a}}$ value of this reaction is $56 \mathrm{~kJ} / \mathrm{mol}$. It should be mentioned that an exothermic peak was observed in the similar temperature range for the pure MI solvent with some shift to the lower temperature and was attributed therefore to the possible reactions of the MI itself. This observation indicates possible incorporation of the MI in the PAI-network structure. In general, it could be concluded that, in contrary to NMP, MI has a significant influence on the final properties of the cured PAI-resin.

\subsection{Isothermal curing in 'ideal' (closed) conditions}

The cure kinetics of thermosetting polymers is conveniently monitored by the DSC technique. Since the PAI cure reaction is an exothermal process, the heat flow measured by DSC is proportional to both the heat release and the cure rate. Thus, the polymerisation degree $\alpha(t)$ at the respective time interval can be determined by Equation (2):

$\alpha(t)=\frac{\Delta H_{\mathrm{t}}}{\Delta H_{\mathrm{total}}}$

where $\Delta H$ is the reaction enthalpy measured at given time $t$ and $\Delta H_{\text {total }}$ is the total reaction enthalpy which can be determined as the area under the exothermal peaks from the non-isothermal DSC scans [29]. In this work, $\Delta H_{\mathrm{t}}$ was taken from the iso-thermal segments of DSC curves by simulating the respective isothermal curing program (see Table 1), whereas $\Delta H_{\text {total }}$ was generated from the non-isothermal scans collected at $3^{\circ} \mathrm{C} / \mathrm{min}$. All isothermal tests were done in high pressure crucibles (so called 'ideal case'), and the conversion for each resin system at each curing program was plotted as a function of time.

The iso-thermal kinetics in terms of conversion curves as well as corresponding temperature profiles are shown in Figures 5a and 5b for NMP_TC(I) and MI_TC(L), respectively. The conversions achieved for both resin systems at respective postcuring temperatures are given in Table 4 . As can be seen, the final conversion for the NMP_TC(I) is much lower compared to the MI_TC(L) for all the curing programs applied (22-41\% compared to $73-$ $99 \%$, respectively). After the initial heating stage (70- $180^{\circ} \mathrm{C}$ for $20 \mathrm{~min}$, titled as non-isol) and the first isothermal stage $\left(20 \mathrm{~min}\right.$ at $180^{\circ} \mathrm{C}$, titled as isoI) the NMP_TC(I) system shows the conversion about $17 \%$. In contrast, the conversion of the MI TC(L) system at similar curing conditions reached about $52 \%$. The second heating stage (non-isoII) changed the conversion of NMP based systems insignificantly (Figure 5a), whereas in MI-media the reaction occurs more intensively and for all MIbased systems reached about $60-70 \%$ (Figure $4 \mathrm{~b}$ ). After the last isothermal stage (isoII) at $215^{\circ} \mathrm{C}$, MI_TC(L)_215 represents more than factor three higher conversion $(\sim 74 \%)$ compared to that of NMP_TC(I)_215 ( 22\%). After the post-curing at $240^{\circ} \mathrm{C}$, the conversion for the MI_TC(L)_240 system is again almost three times higher $(\sim 87 \%)$ in comparison to respective NMP_TC(L)_240 resin ( $\sim 29 \%)$. After the isothermal stage at $270^{\circ} \mathrm{C}$, the MI_TC(L)_270 system shows a conversion value
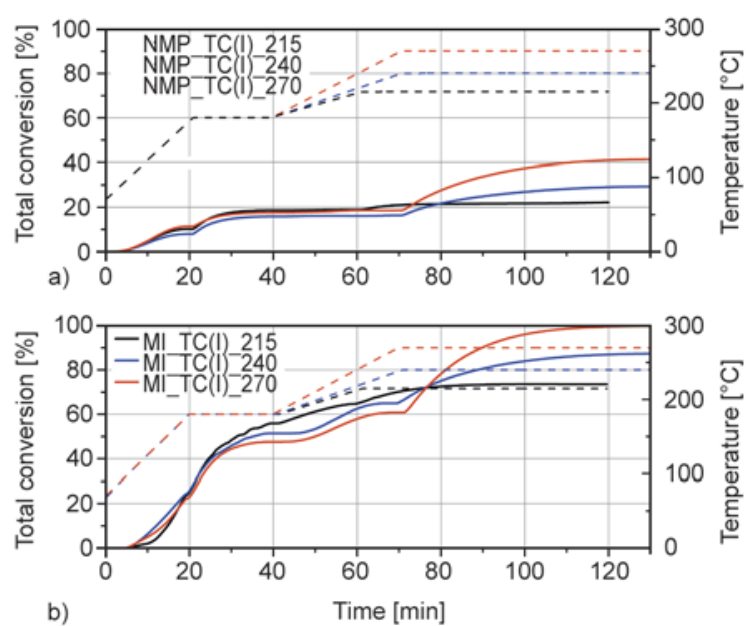

Figure 5. Isothermal curing kinetics of the NMP_TC(I) (a) and MI_TC(L) (b) resins with the respective temperature curing programs 1, 2 and 3 using HPCDSC: conversion curves (solid lines) and their temperature programs (dashed-lines) 
Table 4. Conversion values $\alpha_{\text {non-iso/iso }}$ at different stages of the respective curing programs

\begin{tabular}{|c|c|c|c|c|}
\hline Sample & $\begin{array}{c}\boldsymbol{\alpha}_{\text {non-isoI }} \\
{[\%]}\end{array}$ & $\begin{array}{l}\alpha_{\text {isoI }} \\
{[\%]}\end{array}$ & $\begin{array}{c}\boldsymbol{\alpha}_{\text {non-isoII }} \\
{[\%]}\end{array}$ & $\begin{array}{c}\alpha_{\text {isoII }} \\
{[\%]}\end{array}$ \\
\hline & non-isoI: $70-180^{\circ} \mathrm{C}$ & isol: $20 \mathrm{~min}$ at $180^{\circ} \mathrm{C}$ & non-isoII: $180-215 / 240 / 270^{\circ} \mathrm{C}$ & isoII: $1 \mathrm{~h}$ at $215 / 240 / 270^{\circ} \mathrm{C}$ \\
\hline NMP_TC(I)_215 & 8.8 & 18.4 & 18.9 & 22.2 \\
\hline NMP_TC(I)_240 & 7.0 & 15.6 & 16.3 & 29.3 \\
\hline NMP_TC(I)_270 & 9.6 & 17.4 & 18.5 & 41.3 \\
\hline MI_TC(L)_215 & 24.9 & 55.8 & 64.8 & 73.5 \\
\hline MI_TC(L)_240 & 25.8 & 51.3 & 65.3 & 87.3 \\
\hline MI TC(L) 270 & 22.9 & 47.5 & 60.7 & 99.7 \\
\hline
\end{tabular}

of $\sim 99 \%$, which is more than twice higher compared to the NMP_TC(I)_270 ( 41\%). As can be seen, the highest conversion for all the resins was achieved at the highest post-curing temperatures (isoII stage at $270^{\circ} \mathrm{C}$ ). However, even though, the MI-based resin being post-cured at $215^{\circ} \mathrm{C}$ demonstrated higher conversion than that of NMP-based one at $270^{\circ} \mathrm{C}(73.5 \%$ compared to $41 \%$ respectively). The data observed are in good agreement with the results described in the previous section in terms of activation energies and non-isothermal reaction profiles.

Information taken from non-isothermal kinetics could be also used indirectly for possible explanations of reactions during isothermal curing. For example, up to $20 \mathrm{~min}$ of non-isothermal curing, when high conversion values are already achieved, the temperature reached $180^{\circ} \mathrm{C}$. The main reaction occurring in this temperature interval was identified as the reaction of poly(amic acid) formation (isophtalic conformer, peak 3 in Figure 3 and respective reaction 3 in Figure 4 and Table 3). Therefore, an assumption could be made that this reaction is dominant by heating up to $180^{\circ} \mathrm{C}$ and following isothermal curing stage at this temperature. In NMP solvent, the activation energy $E_{\mathrm{a}}$ of this reaction was found to be $292 \mathrm{~kJ} / \mathrm{mol}$, whereas for the same reaction in MI media the $E_{\mathrm{a}}$ was $93 \mathrm{~kJ} / \mathrm{mol}$. In addition, the enthalpy and intensity of the corresponding exothermal peak in DSC-curves was much more intensive in MI solvent than that observed for NMP (cf. Figure 3). This indicates some possible catalytic effect of MI on the polymerization of PAI-resin at the initial stages of the reaction. Taking into account possible build in of MI in the PAI network structure also, much higher final conversion of PAI in MI media could be explained. Apart from that, one of the very important factors is possible conformational changes of PAI resin in MI media. However, it should be more carefully investigated. Based on the data observed, it can be concluded that the initial stage of the PAI curing plays a dominant role in the formation of the final resin structure.

\subsection{Isothermal curing in 'real' (open) conditions}

Under real conditions, the PAI resins are cured under air atmosphere in thin films. Under such 'open' conditions, the solvent used as resin media evaporates at the beginning of a curing process in the first iso-thermal reaction step. After that the samples weight changes insignificantly and it occurs due to the evaporation of by-products of the cyclization reaction. The weight of the final samples can slightly differ depending on the final curing temperatures and is connected to the final conversion. As result, it can have an important influence on the final properties of the PAI thin films.

\subsubsection{Thermal stability of the cured PAI-films}

TGA-curves and their differential representations (DTG) vs. temperature of NMP- and MI-based PAI are presented in Figures $6 \mathrm{a}$ and $6 \mathrm{~b}$ for the PAI samples cured in open conditions using temperature programs 1 and 3, respectively.

As can be seen, mass loss of the PAI samples is a multistage process. Peaks of the low intensity in the temperature range up to $150^{\circ} \mathrm{C}$ correspond to the evaporation of absorbed moisture. The first intensive peak in the range of $200-400^{\circ} \mathrm{C}$ represents the evaporation of the post-polymerization byproducts (e.g. $\mathrm{HCl}, \mathrm{H}_{2} \mathrm{O}$ ). It is noteworthy that this peak (peak 1 in Figure 6) demonstrates significantly reduced intensity when the PAI films are cured using program 3 with a post-curing temperature of $270^{\circ} \mathrm{C}$. It confirms that the higher conversion/ imidization degree of the PAI at higher cure-temperatures increases its thermal stability. At the same time, the MI-based PAI samples demonstrated notable shift of the Peak1 (reaction byproducts elim- 

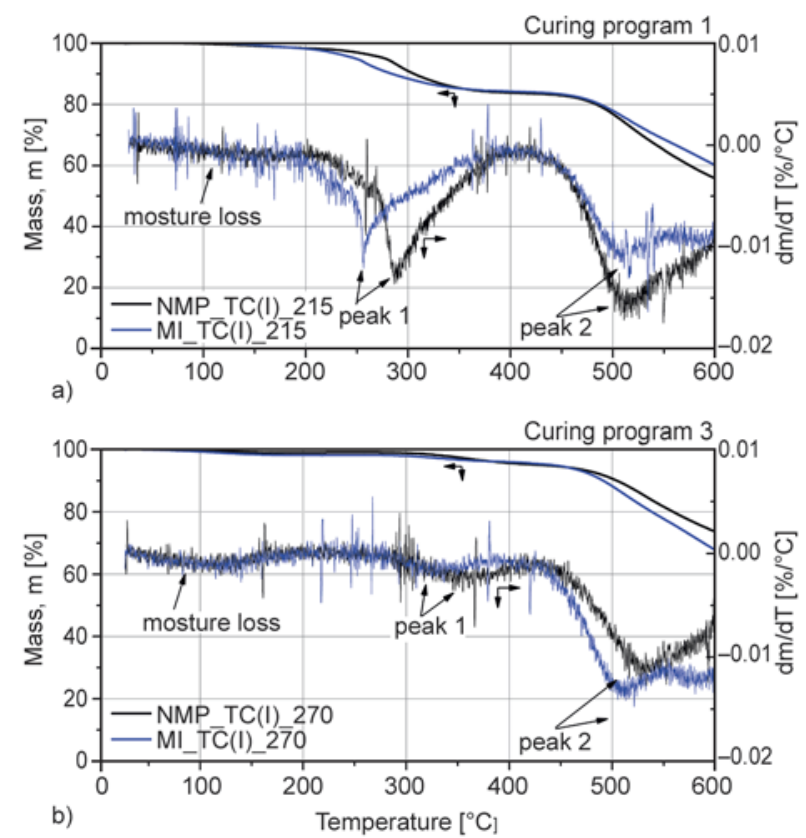

Figure 6. TGA- (left axes) and DTG- (right axes) curves vs. temperature for NMP_TC(I) and MI_TC(L) cured using programs 1 (a) $\overline{3}$ (b), respectively

ination) to the lower temperatures (up to $30^{\circ} \mathrm{C}$ ) in comparison to the NMP based ones, independently on the post-curing temperature applied. It confirms a catalytic effect of MI on the PAI-curing reaction, which was also observed in the curing kinetics and activation energy values discussed above.

The second intensive peak was observed in the high-temperature range $\left(\sim 400-600^{\circ} \mathrm{C}\right)$. It corresponds to the thermal degradation of the PAI resins with onsets at $\sim 430^{\circ} \mathrm{C}$ for NMP_TC(I) and $\sim 420^{\circ} \mathrm{C}$ for MI_TC(L), which is in agreement with results of other authors for polyimide-systems [30]. As can be concluded, the thermostability of cured PAI films is marginally influenced by the solvent used.

\subsubsection{Conversion of the PAI films cured under 'real' conditions}

Due to the strong endothermal effect of the solvent evaporation in reactive PAI resins under 'open' conditions, determination of their final conversion values using DSC technique is not possible. However, according to the Di Benedetto's equation, the final conversion can be calculated from the information on the glass transition temperature of the finally cured resin $\left(T_{\mathrm{g}}\right)$. For that, $T_{\mathrm{g}}$ of the uncured resin $\left(T_{\mathrm{g}}, \min \right)$ and $T_{\mathrm{g}}$ after "complete" curing $\left(T_{\mathrm{g}, \max }\right)$ should be known [31].

In order to estimate the conversion values of the PAI films cured under real conditions according to the Di Benedetto equation, the samples with the highest polymerization degree were obtained using post-cure for 20 hours at $290^{\circ} \mathrm{C}$ (program 4 - Table 1) followed by repeated heating up to $375^{\circ} \mathrm{C}$ (thermal stability limit obtained from TGA data) until a shift of the glass transition temperature $\left(T_{\mathrm{g}}\right)$ was less than $1^{\circ} \mathrm{C}$ (Figure 6). After that the last heating scan was run up to $450^{\circ} \mathrm{C}$ to find out the range of rubberelasticity plateau.

Although the complete network formation for PAI resins is hardly possible and strongly depends on the curing conditions, the network obtained in such manner was assumed as the fully crosslinked ('ideal' network) and its $T_{\mathrm{g}}$ and storage modulus $\left(E^{\prime}\right)$ values were used for further calculations of conversion and cross-link density.

For the NMP_TC(I), $T_{\mathrm{g}}$ displacement less than $1{ }^{\circ} \mathrm{C}$ was observed after the $20^{\text {th }}$ repeat-scanning till $375^{\circ} \mathrm{C}$ (Figure $7 \mathrm{a}, 7 \mathrm{~b}$ ). The $21^{\text {st }}$ scan was run up to $450^{\circ} \mathrm{C}$ to determine the plateau. The value of respective $T_{\mathrm{g} \text {, max }}$ was found at $\sim 241^{\circ} \mathrm{C}$ red at maximum range of $\tan \delta$ and used for conversion determination by Di Benedetto equation (Table 5 ). The estimated values of $T_{\text {plateau }}\left(\sim 430^{\circ} \mathrm{C}\right)$ and $E_{\text {plateau }}^{\prime}$ ( $\sim 673 \mathrm{MPa})$ were used for the calculation of the 'idealized' crosslink density and are given in Table 6.

For the MI_TC(L) only 12 heating DMA-scans were performed (see Figure 7c, 7d). The test samples always broke after the $12^{\text {th }}$ heating suggesting its higher brittleness. For this reason, the $E_{\text {plateau value }}^{\prime}$ and the corresponding rubbery plateau temperature onset ( $\left.T_{\text {plateau }}\right)$ were calculated using an approximation approach described below.

In order to estimate, if the acquired DMTA values are able to provide an adequate approximation model, the values of storage modulus at the glass transition temperature were plotted as an exponential function of glass transition temperature determined as the peak temperature on the tan $\delta$ curves (Figure 8). As can be seen, the glass transition temperature $T_{\mathrm{g}}$ slowly reaches an equilibrium which allows performing such modeling. Similar to that, the temperatures of the plateau onset ( $T_{\text {plateau }}$ ) from the $E^{\prime}$ curves were plotted versus $T_{\mathrm{g}}$ and the found extrapolated value of the $T_{\text {plateau }}$ of the $12^{\text {th }}$ DMTA run is $\sim 388^{\circ} \mathrm{C}$. In similar manner the $E_{\text {plateau was deter- }}^{\prime}$ mined and was found as $\sim 18 \mathrm{MPa}$.

The conversion $\alpha(0 \leq \alpha \leq 1)$ at 'real' conditions was calculated from Di Benedetto's equation (Equation (3)) [31]: 

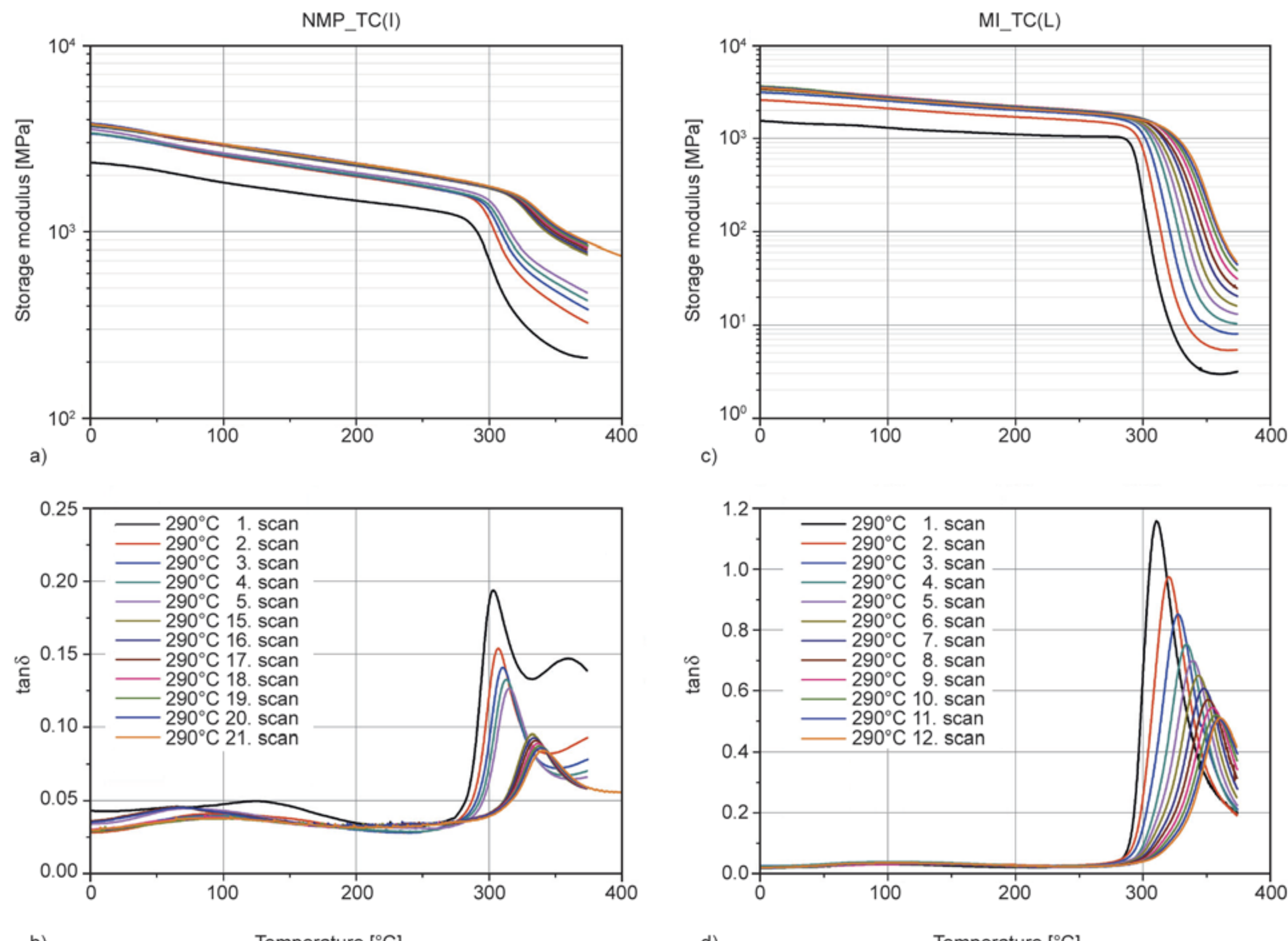

c)

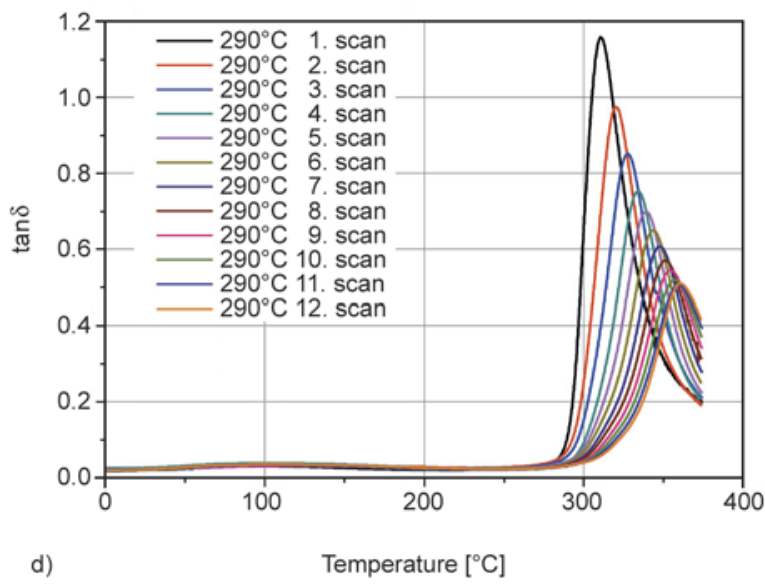

Figure 7. Storage modulus $E^{\prime}$ (a, c) and loss factor $\tan \delta(b, d)$ as a function of temperature for the systems NMP_TC(I) (left) and MI_TC(L) (right) cured with program 4 at repeated scanning on the same test specimens. Final post-curing temperature and number of the scans are given in the legend; legend in (b) and (d) also belongs to (a) and (c).

$\frac{T_{\mathrm{g}}-T_{\mathrm{g}, \min }}{T_{\mathrm{g}, \max }-T_{\mathrm{g}, \min }}=\frac{\lambda \alpha}{1-(1-\lambda) \alpha}$

where $\lambda$ is determined by Equation (4) [32, 33]:

$\lambda=\frac{T_{\mathrm{g}, \min }}{T_{\mathrm{g}, \max }}$

here $T_{\mathrm{g}, \min }$ was determined by DSC using stochastically thermo-modulated method $\left(\right.$ TOPEM $\left.^{\circledR}\right)$. The glass transition temperature of the 'fully' crosslinked system $T_{\mathrm{g}, \max }$ was estimated from the multicycled DMTA testing. The conversions calculated

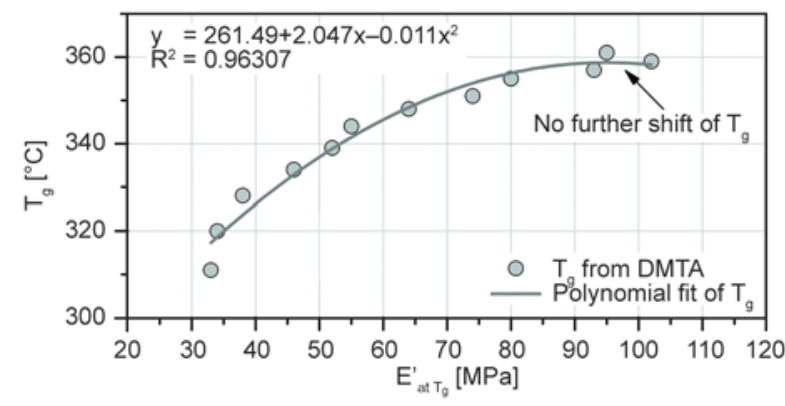

Figure 8. Determination of the $T_{\mathrm{g}, \max }$ approximation approach. Similar approximations were done for $T_{\text {plateau }}$ and $E_{\text {plateau. }}^{\prime}$ Explanations are given in text.

Table 5. Conversions in real conditions determined according to Di Benedetto

\begin{tabular}{|c|c|c|c|c|c|}
\hline Sample name & $\begin{array}{l}\mathbf{T}_{\mathrm{g}, \min } \\
{\left[{ }^{\circ} \mathbf{C}\right]}\end{array}$ & $\begin{array}{l}\mathbf{T}_{\mathbf{g}, \max } \\
{\left[{ }^{\circ} \mathbf{C}\right]}\end{array}$ & $\begin{array}{c}\mathbf{T g} \\
{\left[{ }^{\circ} \mathbf{C}\right]}\end{array}$ & $\lambda$ & $\begin{array}{c}\text { Total conversion } \alpha \\
{[\%]}\end{array}$ \\
\hline NMP_TC(I)_215 & \multirow{3}{*}{-101} & \multirow{3}{*}{341} & 169 & \multirow{3}{*}{0.28} & 85 \\
\hline NMP_TC(I)_240 & & & 207 & & 89 \\
\hline NMP_TC(I)_270 & & & 225 & & 91 \\
\hline MI_TC(L)_215 & \multirow{3}{*}{-121} & \multirow{3}{*}{361} & 193 & \multirow{3}{*}{0.24} & 89 \\
\hline MI_TC(L)_240 & & & 222 & & 91 \\
\hline MI_TC(L)_270 & & & 225 & & 91 \\
\hline
\end{tabular}


via the Di Benedetto's equation for both resin systems are listed in Table 5.

The calculated total conversions at real conditions for both MI and NMP based systems, have been found to be similar and they all are in the range of $85-93 \%$ with marginal tendency to increase at rise of the final post-cure temperature $(215,240$ or $270^{\circ} \mathrm{C}$ ). Thus, in order to make further statements on the final properties of the investigated resins, the viscoelastic properties and their crosslink densities were carefully investigated.

\subsubsection{Viscoelastic behavior and crosslink density}

The DMA results (temperature dependencies of storage modulus $E^{\prime}$ and loss factor tan $\delta$ ) for the cured samples NMP_TC(I) and MI_TC(L) are presented in Figure 9. As can be seen, all PAI-systems postcured at 215,240 and $270^{\circ} \mathrm{C}$ demonstrate complicate storage modulus profile and several peaks on $\tan \delta$ traces. For NMP based samples at increase of
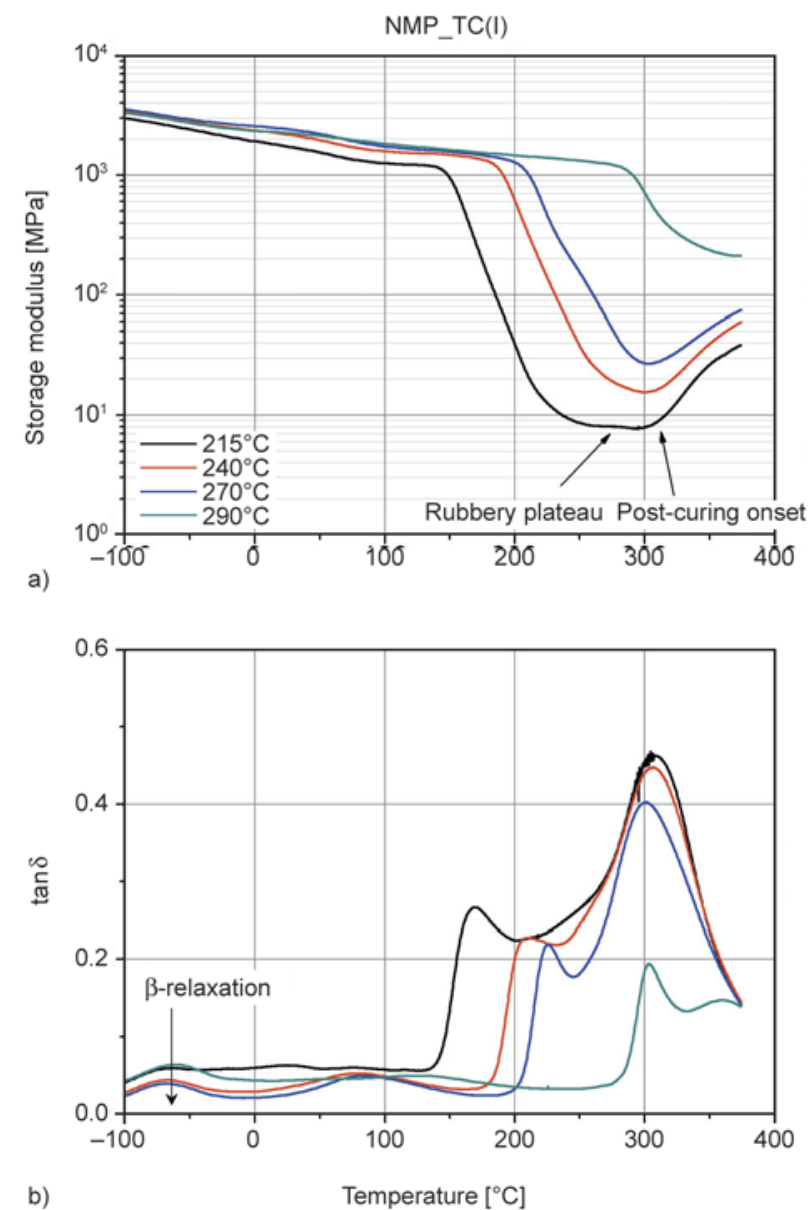

the post-curing temperature the $E^{\prime}$ values at room temperature and in the rubbery state increase indicating improvement of mechanical stiffness of the PAI films cured at higher temperatures. Increase of the $E^{\prime}$ in the rubbery state was determined for all samples regardless the post-curing temperature. This indicates further post-curing effects. The $\tan \delta$ curves clearly demonstrate a shift of the first $\alpha$-relaxation peak to the right with increase of the post-curing temperature. This shift of $T_{\mathrm{g}}$ indicates that for NMP-based PAI systems the curing program with the post-curing temperature at $215^{\circ} \mathrm{C}$ is too low which result in incomplete cure. These data play in tact with the conversion determined by Di Benedetto approach, where the calculated conversion of NMP_TC(I)_215 (see Table 5) was $\sim 85 \%$ and for the NMP_TC(I)_270 it slightly increases up to $\sim 91 \%$.

At the same time the second peak of $\tan \delta$ corresponds to the $T_{\mathrm{g}}$ of the post-cured system and is not changed with increase of the final curing tempera-
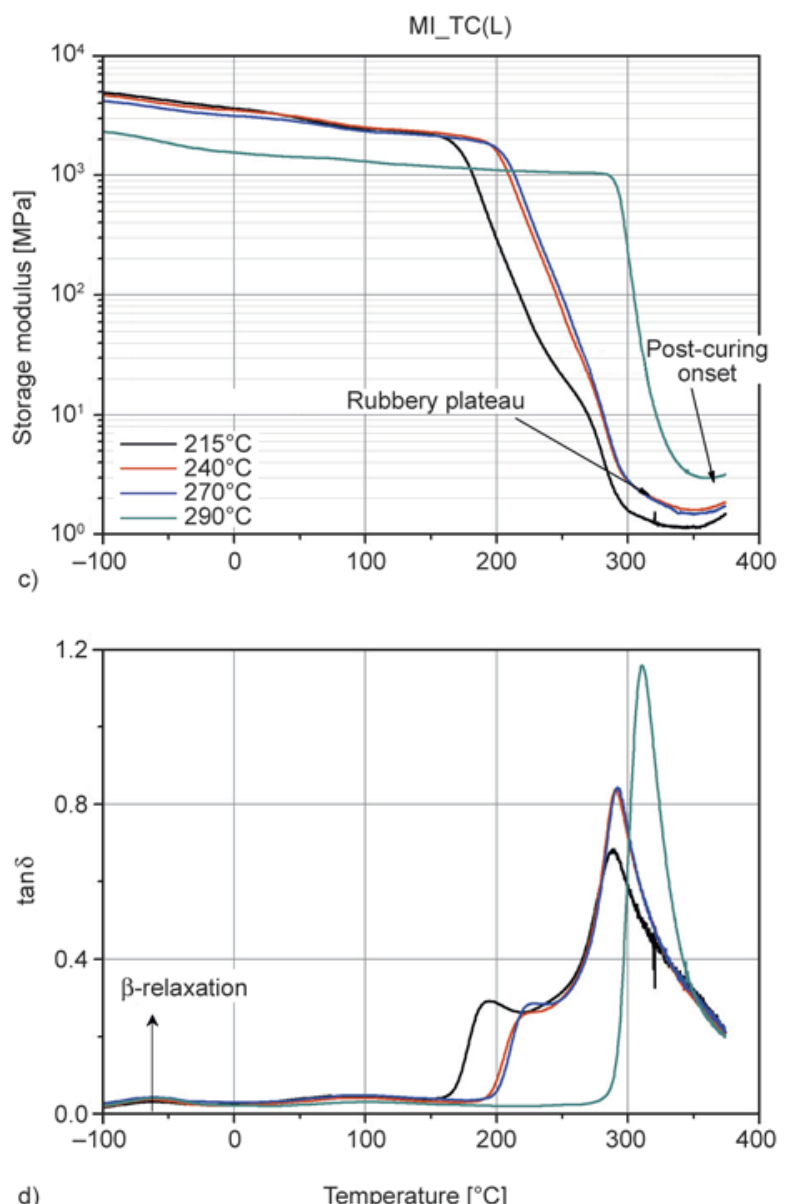

d)

Figure 9. Storage modulus $E^{\prime}$ (a, c) and loss factor $\tan \delta(b, d)$ as a function of temperature for the NMP_TC(I) (left) and MI_TC(L) (right) systems cured at different curing programs (their final post-curing temperatures are given in the legend); legend in (a) and (c) also belongs to (b) and (d) 
ture. It indicates that for all these systems similar post-reaction processes take place. When the samples were post-cured at $290^{\circ} \mathrm{C}$, the first $T_{\mathrm{g}}$ disappeared and only the high-temperature $\tan \delta$ peak was observed.

Similar tendency of $T_{\mathrm{g}}$ increase with rise of postcuring temperature was also found for the MI-PAI system. At the same time, the samples post cured at 240 and $270^{\circ} \mathrm{C}$ demonstrate similar behavior. It indicates that increase of the post-curing temperature up to $270^{\circ} \mathrm{C}$ has marginal effect on the viscoelastic properties of the MI-PAI-resin and the lower temperatures can be applied with similar efficiency. It has to be noted that the $T_{\mathrm{g}}$ shift at increase of the postcuring temperature is not so pronounced as for NMPbased resin which is in good agreement with the conversion values of these systems (c.f. Table 5).

One can see that the $E^{\prime}$ values of the NMP-based PAI resins in rubbery state are higher than those of MI-based ones, which can indicate the difference in their crosslink density.

For the crosslinked polymers, mechanical properties in the viscoelastic state are related to the network structure. Then, their crosslink density can be determined from Equation (5) $[34,35]$, which was also used by other authors for the determination of the crosslink density for highly crosslinked imidecompounds [8] (Equation (5)):

$n_{\mathrm{c}}=\frac{E_{\text {plateau }}^{\prime}}{3 R T_{\text {plateau }}}$

where $n_{\mathrm{c}}$ is the crosslink density (molar concentration of junction points per volume unit) $\left[\mathrm{mol} / \mathrm{cm}^{3}\right]$; $E_{\text {plateau }}^{\prime}$ is the storage modulus in rubbery region; $R$ is the gas constant $\left[\mathrm{MPa} \cdot \mathrm{cm}^{3} /(\mathrm{mol} \cdot \mathrm{K})\right] ; T_{\text {plateau }}$ is the absolute temperature of $E_{\text {plateau }}^{\prime}$ taken [K].

Since the $E^{\prime}$ rises at the glass transition due to the post-curing effects, the values of the $E_{\text {plateau }}^{\prime}$ were taken as the lowest points of the $E^{\prime}$ in the rubbery region before the obvious post-curing occurs. The values of the $E^{\prime}$ determined at $30^{\circ} \mathrm{C}\left(E_{30^{\circ} \mathrm{C}}^{\prime}\right)$, the $T_{\mathrm{g}}$ determined from the first $\tan \delta$ peak, temperature of the rubbery plateau ( $\left.T_{\text {plateau }}\right)$ and corresponding modulus value ( $\left.E_{\text {plateau }}^{\prime}\right)$ as well as the results of the crosslink densities of both tested PAI systems are summarized in Table 6.

An increase of the final curing temperature has a significant effect on the final network formation. It is noteworthy that at increase of the final curing temperature from 215 to $240^{\circ} \mathrm{C}$ and from 240 to $270^{\circ} \mathrm{C}$, the crosslink density of the NMP_TC(I) system increases almost twice. For the 'perfectly' crosslinked network (determined after 21 DMA-scans as described above) the $n_{\mathrm{c}}$ value is several times higher and is $41194 \mathrm{~mol} / \mathrm{m}^{3}$ (see Table 6). Simultaneous to $n_{\mathrm{c}}$ increase of the $T_{\mathrm{g}}$ and $E^{\prime}$ at room temperature indicates the formation of more rigid and denser PAI network at higher post-curing temperature.

Surprisingly, the MI based PAI resin showed different behavior. For this system the crosslink density and $T_{\mathrm{g}}$ values rise insignificantly with the post-curing temperature, whereas $E^{\prime}$ at room temperature slightly decreases or stays constant in case of the 'perfectly' cured network (after 12 DMA-scans: c.f. Table 6). Moreover, the $n_{\mathrm{c}}$ values of MI_TC(L) systems are significantly lower than those of respective NMP-based ones. At the same time, the storage moduli in glassy state (before $T_{\mathrm{g}}$ ) for MI-PAI systems are higher compared to NMP-based ones. It is noteworthy that, in contrast to the NMP-based systems, at increase of the last curing temperature step from 215 to $270^{\circ} \mathrm{C}$ intensity of the $\beta$-relaxation peak in $\tan \delta$ curves rises (see Figure $9 \mathrm{~b}$ and $9 \mathrm{c}$, effect of the temperature increase on the $\beta$-relaxation intensity is showed with arrows). Similar behavior was found for the internally antiplasticized epoxy systems. Thus, internal antiplasticization effects were observed for the epoxy resins (EP) hybridized with benzoxazines at increase of EP functionality [36]. In our case, increase of free volume at lower crosslink density of the MI based PAI polymer system promotes associations of small moieties and pendant groups causing an improved antiplasticization effect at lower post-curing temperature. This is confirmed by rise of storage modulus in the glassy state, decrease of the $\beta$-transition intensity, and tendency to reduction of $T_{\mathrm{g}}$ value by decreasing post-curing temperature.

Obviously, a catalytic effect of $\mathrm{N}$-methylimidazole increases the reaction efficiency on the stage of the macromolecule growth and imidization. The latter is also confirmed by the results of the non-isothermal curing kinetics with preferable formation of longer fully imidized linear chain fragments at high conversion degree where $E_{\mathrm{a}}$ values of the corresponding reactions (titled as 3 and 4 in Table 3 and Figure 4) are much lower than those for the NMP-based determined from the isothermal curing kinetics tested at 'ideal' conditions. The higher values of the glass transition temperature for the MI-based PAI compared to the NMP-based ones can be explained by possi- 
Table 6. Overview of the values acquired by DMA-measurements and of the calculated crosslinking density $\left(n_{\mathrm{c}}\right)$ for both investigated PAI resins

\begin{tabular}{|l|l|c|c|c|c|c|}
\hline \multirow{2}{*}{ Resin system } & \multicolumn{1}{|c|}{$\begin{array}{c}\text { Curing program } \\
\text { (post-curing temperature) }\end{array}$} & $\begin{array}{c}\mathbf{E}^{\prime}{ }_{\mathbf{3 0}}^{\circ} \mathbf{C} \\
{[\mathbf{M P a}]}\end{array}$ & $\begin{array}{c}\mathbf{T}_{\mathbf{g}} \\
{\left[{ }^{\circ} \mathbf{C}\right]}\end{array}$ & $\begin{array}{c}\text { Onset } \mathbf{T}_{\text {plateau }} \\
{\left[{ }^{\circ} \mathbf{C}\right]}\end{array}$ & $\begin{array}{c}\mathbf{E}_{\text {plateau }}^{\prime} \\
{[\mathbf{M P a}]}\end{array}$ & $\begin{array}{c}\mathbf{n}_{\mathbf{c}} \\
{\left[\mathbf{m o l} / \mathbf{m}^{3}\right]}\end{array}$ \\
\hline \multirow{4}{*}{ NMP_TC(I) } & Program $1\left(215^{\circ} \mathrm{C}\right)$ & 1697 & 169 & 258 & 8 & 604 \\
\cline { 2 - 7 } & Program 2 $\left(240^{\circ} \mathrm{C}\right)$ & 2149 & 207 & 296 & 16 & 1092 \\
\cline { 2 - 7 } & Program $3\left(270^{\circ} \mathrm{C}\right)$ & 2411 & 225 & 302 & 27 & 1883 \\
\cline { 2 - 7 } & Program 4 21. scan $\left(290^{\circ} \mathrm{C}\right)$ & 3550 & 342 & 430 & 673 & 41194 \\
\hline \multirow{3}{*}{ MI_TC(L) } & Program $1\left(215^{\circ} \mathrm{C}\right)$ & 3647 & 193 & 360 & 3 & 188 \\
\cline { 2 - 7 } & Program 2 $\left(240^{\circ} \mathrm{C}\right)$ & 3514 & 222 & 367 & 5 & 335 \\
\cline { 2 - 7 } & Program 3 $\left(270^{\circ} \mathrm{C}\right)$ & 3161 & 225 & 371 & 8 & 498 \\
\cline { 2 - 7 } & Program 4 $12 . \operatorname{scan}\left(290^{\circ} \mathrm{C}\right)$ & 3503 & 361 & $388^{*}$ & $18^{*}$ & 1065 \\
\hline
\end{tabular}

*the values are found using the approximation approach. Note: all systems of program 4 were subjected to multiple DMA-tests cycling until fracture (e.g. 21 scans for NMP-PAI, whereas 12 scans for MI-PAI).

ble incorporation of the MI units into the aromatic structure of PAI network increasing the stiffness of the system in addition to better realization of the polyimidization/polycyclization reactions [37].

\section{Conclusions}

$\mathrm{N}$-methylimidazole is a material, not used so far as a solvent for the manufacturing of polyamide-imide resins. However, it provides several benefits and positive effects on the PAI curing process and the final material properties. In this work, use of the highpressure DSC-crucibles allowed investigations of the PAI curing kinetics preserving the reactive media constant and avoiding its influence on the exothermal reaction. In such conditions, several reaction peaks were recognized.

Analyzing the final properties of the PAI resins cured under 'real' conditions and the data of the nonisothermal curing kinetics in 'ideal' (closed) conditions the following conclusions can be drawn. The imidization reactions of the iso- and terephtalic conformers of the PAI resin in MI media have much lower activation energy than in the NMP one. It indicates that MI-media is more preferable for the curing of PAI-resin and catalyzes the PAI polymerization reaction shifting the 'low-temperature' reactions to the lower temperatures. At the same time, MI has no obvious effect on the 'high-temperature' postcuring reaction. Investigation of the PAI reaction at isothermal conditions simulating the real curing, the final completeness of the conversion was significantly higher for the MI-based resins, compared to the conventional NMP-based ones for all the curing programs applied. It confirms again the results observed at the non-isothermal investigations.
From their viscoelastic properties, it was determined that MI-based PAI-system shows two times higher storage modulus at $30^{\circ} \mathrm{C}\left(E^{\prime}{ }_{30^{\circ}} \mathrm{C}\right)$ in comparison to the conventional NMP-PAI resin when the lowest final curing temperature was used. For the MI-based resins, simultaneously to the lowering of the $E_{30^{\circ} \mathrm{C}}^{\prime}$, the crosslink density $n_{\mathrm{c}}$ slightly increased at rise of the post-curing temperature, whereas for the NMP-PAI samples the $E_{30^{\circ} \mathrm{C}}^{\prime}$ rises together with the $n_{\mathrm{c}}$ values. Such untypical behavior of the MI-PAI was explained with possible internal antiplasticization effect and build in of aromatic MI-units in the structure of PAI-network. The latter was assumed from the reaction peak observed on the DSC traces of the neat MI-solvent.

Summarized, the observed results make N-methylimidazole very promising for the use as a PAI-resin solvent. Further, due to its lower toxicity, it is extremely attractive for the production of PAI systems with outstanding and tunable properties.

\section{Acknowledgements}

The authors are thankful to Prof. Dr. h.c. József KargerKocsis for the helpful discussions and to Mettler Toledo GmbH (Giessen, Germany), especially to Mr. Peter Bamfaste, for the kind support and technical cooperation.

\section{References}

[1] Gebhard A., Haupert F., Schlarb A. K.: Development of nanostructured slide-coatings for automotive components. in 'Tribology of polymeric nanocomposites' (eds.: Friedrich K., Schlarb A. K.) Elsevier, Oxford, Vol 55, 619-648 (2008). DOI: $10.1016 / \mathrm{B} 978-0-444-59455-6.00018-0$

[2] Fink J. K.: Poly(amide-imide)s in 'High performance polymers' (ed.: Ebnesajjad S.) Elsevier, New York, 321-366 (2014). 
[3] Murray T.: Poly(amide-imides): Wire enamels with excellent thermal and chemical properties. Macromolecular Materials and Engineering, 293, 350-360 (2008). DOI: $10.1002 /$ mame.200700365

[4] Hong Y-T., Jin M. Y., Suh D. H., Lee J-H., Choi K-Y.: New preparation method of poly(amide-imide)s using direct polycondensation with thionyl chloride and their characterization. Die Angewandte Makromolekulare Chemie, 248, 105-122 (1997).

DOI: 10.1002/apmc.1997.052480107

[5] Underwood G.: Polyamide-imide (PAI). in 'Engineering plastics handbook' (ed.: Margolis J. M.) McGrawHill, Montreal, 257-285 (2006).

DOI: $10.1036 / 0071457674$

[6] Russell J. D., Kardos J. L.: Modeling the imidization kinetics of AFR700B polyimide. Polymer Composites, 18, 64-78 (1997). DOI: $10.1002 / p c .10262$

[7] Kim Y. J., Glass T. E., Lyle G. D., McGrath J. E.: Kinetic and mechanistic investigations of the formation of polyimides under homogeneous conditions. Macromolecules, 26, 1344-1358 (1993). DOI: $10.1021 / \mathrm{ma} 00058 \mathrm{a} 024$

[8] Kimura H., Ohtsuka K., Matsumoto A., Fukuoka H., Oishi Y.: Synthesis and characterization of phenylethynylcarbonyl terminated novel thermosetting imide compound. Express Polymer Letters, 7, 161-171 (2013). DOI: $10.3144 /$ expresspolymlett.2013.15

[9] Chang K. C., Hsu C. H., Lu I. H., Ji W. F., Chang C. H., Li W. Y., Chuang T. L., Yeh J. M., Liu W. R., Tsai M. H.: Advanced anticorrosive coatings prepared from electroactive polyimide/graphene nanocomposites with synergistic effects of redox catalytic capability and gas barrier properties. Express Polymer Letters, 8, 243-255 (2014).

DOI: $10.3144 /$ expresspolymlett.2014.28

[10] Harris F. W.: Synthesis of aromatic polyimides from dianhydrides and diamines. in 'Polyimides' (eds: Wilson D., Stenenberger H. D., Hergenrother P. M.) Springer Netherlands, 1-37 (1990).

[11] Eckert C. A., Knutson B. L., Debenedett P. G.: Supercritical fluids as solvents for chemical and materials processing. Nature, 383, 313-318 (1996).

DOI: $10.1038 / 383313 \mathrm{a} 0$

[12] Chen K-L., Shen Y-H., Yeh M-Y., Wong F. F.: Complexes of imidazole with poly(ethylene glycol)s as the thermal latency catalysts for epoxy-phenolic resins. Journal of the Taiwan Institute of Chemical Engineers, 43, 306-312 (2012).

DOI: $10.1016 /$ j.jtice.2011.08.007

[13] Chafin R. W. II: Torlon ${ }^{\circledR}$ and silicalite mixed matrix membranes for xylene isomer purfication. $\mathrm{PhD}$ thesis, Georgia Institute of Technology, Atlanta (2007).

[14] Robertson G., Guiver D. M., Yoshikawa M., Brownstein S.: Structural determination of Torlon ${ }^{\circledR}$ 4000T polyamide-imide by NMR spectroscopy. Polymer, 45, 1111-1117 (2004).

DOI: $10.1016 /$ j.polymer.2003.12.029
[15] Lin Y-S., Liu C-W., Tsai T. Y. R.: 1-methylimidazole 3$\mathrm{N}$-oxide as a new promoter for the Morita-Baylis-Hillman reaction. Tetrahedron Letters, 46, 1859-1861 (2005). DOI: 10.1016/j.tetlet.2005.01.099

[16] Kreuz J. A., Endrey A. L., Gay F. P., Sroog C. E.: Studies of thermal cyclizations of polyamic acids and tertiary amine salts. Journal of Polymer Science Part A-1: Polymer Chemistry, 4, 2607-2616 (1966).

DOI: $10.1002 /$ pol.1966.150041023

[17] Yang C-P.: Synthesis of polymers containing pyromellitdiimide and benzimidazole or pyrrolobenzimidazole moieties and of their corresponding model compounds. Die Makromolekulare Chemie, 187, 25092523 (1986). DOI: $10.1002 / \mathrm{macp} .1986 .021871101$

[18] Lauver R. W.: Kinetics of imidization and crosslinking in PMR polyimide resin. Journal of Polymer Science: Polymer Chemistry Edition, 17, 2529-2539 (1979). DOI: $10.1002 /$ pol.1979.170170825

[19] Chu N-J., Huang J-W.: Reactivity of poly(amic acid) isomers in thermal imidization. Polymer Journal, 22, 725-732 (1990).

DOI: $10.1295 /$ polymj.22.725

[20] Barral L., Cano J., López J., López-Bueno I., Nogueira P., Abad M. J., Ramírez C.: Kinetic studies of the effect of ABS on the curing of an epoxy/cycloaliphatic amine resin. Journal of Polymer Science Part B: Polymer Physics, 38, 351-361 (2000).

DOI: 10.1002/(SICI)1099-0488(20000201)38:3<351:: AID-POLB1>3.0.CO;2-C

[21] Núñez L., Fraga F., Núñez M. R., Villanueva M.: Thermogravimetric study of the decomposition process of the system $\operatorname{BADGE}(n=0) / 1,2$ DCH. Polymer, 41, 46354641 (2000).

DOI: 10.1016/S0032-3861(99)00687-4

[22] Gagliano R. A. Jr., Knowlton R. C., Byers L. D.: Methylimidazole-catalyzed ester hydrolysis: Nonlinear kinetics. Journal of Organic Chemistry, 54, 52475250 (1989).

DOI: $10.1021 / \mathrm{jo00283a015}$

[23] Wang H-L., O’Malley M., Fernandez J. E.: Electrochemical and chemical polymerization of imidazole and some of its derivatives. Macromolecules, 27, 893-901 (1994).

DOI: $10.1021 / \mathrm{ma} 00082 \mathrm{a} 003$

[24] Peter K., Vollhardt C., Schore N. E., Butenschön H.: Organische chemie. Wiley, Weinheim (2011).

[25] Takekoshi T.: Synthesis of polyimides. in 'Polyimides: Fundamentals and applications' (eds: Ghosh M. K., Mittal K. L.) Marcel Dekker, New York, 7-48 (1996).

[26] Hofmann K.: Chemistry of heterocyclic compounds: Imidazole and its derivatives, Part I. Wiley, New York (1953).

DOI: $10.1002 / 9780470186541$ 
[27] Harreus A. L., Backes R., Eichler J-O., Feuerhake R., Jäkel C., Mahn U., Pinkos R., Vogelsang R.: 2-Pyrrolidone. in 'Ullmann's encyclopedia of industrial chemistry' Wiley, Weinheim (2002).

DOI: $10.1002 / 14356007 . a 22$ 457.pub2

[28] Chu N-J., Huang J-W., Chang C. H., Whang W. T.: Solvent effects on chain structure and conformation of poly (amic acids) and their crystallosolvate formation. Die Makromolekulare Chemie, 190, 1799-1808 (1989).

DOI: $10.1002 / \mathrm{macp} .1989 .021900805$

[29] Liang G., Chandarashekhara K.: Cure kinetics and rheology characterization of soy-based epoxy resin system. Journal of Applied Polymer Science, 102, 3168-3180 (2006).

DOI: 10.1002/app.24369

[30] Uğur M. H., Toker R. D., Kayaman-Apohan N., Güngör A.: Preparation and characterization of novel thermoset polyimide and polyimide-peo doped with $\mathrm{LiCF}_{3} \mathrm{SO}_{3}$. Express Polymer Letters, 8, 123-132 (2014). DOI: $10.3144 /$ expresspolymlett.2014.15

[31] Di Benedetto A. T.: Prediction of the glass transition temperature of polymers: A model based on the principle of corresponding states. Journal of Polymer Science Part B: Polymer Physics, 25, 1949-1969 (1987). DOI: 10.1002/polb.1987.090250914

[32] Pascault J. P., Williams R. J. J.: Relationships between glass transition temperature and conversion. Polymer Bulletin, 24, 115-121 (1990). DOI: $10.1007 / \mathrm{BF} 00298330$
[33] Pascault J. P., Williams R. J. J.: Glass transition temperature versus conversion relationships for thermosetting polymers. Journal of Polymer Science Part B: Polymer Physics, 28, 85-95 (1990). DOI: $10.1002 /$ polb.1990.090280107

[34] Hofmann K., Glasser W. G.: Cure monitoring of an epoxy-amine system by dynamic mechanical thermal analysis (DMTA). Thermochimica Acta, 166, 169-184 (1990).

DOI: $10.1016 / 0040-6031(90) 80179-3$

[35] Gent A. N.: Rubber elasticity: Basic concepts and behavior. in 'Science and technology of rubber' (eds: Mark J. E., Erman B., Eirich F. R.) Elsevier, Amsterdam, 1-27 (2005).

DOI: 10.1016/B978-012464786-2/50004-3

[36] Grishchuk S., Schmitt S., Vorster O. C., Karger-Kocsis J.: Structure and properties of amine-hardened epoxy/ benzoxazine hybrids: Effect of epoxy resin functionality. Journal of Applied Polymer Science, 124, 28242837 (2012).

DOI: 10.1002/app.35302

[37] Connors K. A., Pandit N. K.: N-methylimidazole as a catalyst for analytical acetylations of hydroxy compounds. Analytical Chemistry, 50, 542-544 (1978). DOI: $10.1021 /$ ac50033a038 